\title{
Assessement of the Correction of Rectus Abdominis Muscles Diastasis Using Two Different Techniques
}

\author{
NADA A. MAHMOUD, M.D.* and WAFAA R. ABD EL-HAMED, M.D.** \\ The Departments of Plastic, Burn and Maxillofacial Surgery* and Radio Diagnosis**, Faculty of Medicine, \\ Ain Shams University, Cairo, Egypt
}

\begin{abstract}
Introduction: The technique used for correction of rectus abdominis diastasis has been a debatable issue since the original description of abdominoplasty. The aim of this study is to assess the durability of the correction of midline diastases done by two different techniques (the rectus abdominis myofascial release technique and the conventional midline plication) and their effect on waist enhancement and its safety in the terms of the intraabdominal pressure changes and respiratory affection that occur after plication.
\end{abstract}

Patients and Methods: The study was conducted on 12 females with body mass index less than 30, having Rohrich type IV B deformities. The patients were divided randomly into two groups based on the technique used for plication of anterior rectus sheath: Group (A) 6 patients underwent myofascial release technique, while group (B) 6 patients underwent conventional midline plication. The two groups were compared as regards; 1 - The width of rectus diastasis using computed tomography of their anterior rectus abdominis sheath pre-and post-operatively at 1 and 6 and as regards 3 points: (A) At the umbilicus, (B) Midway between umbilicus and xiphoid process and (C) Midway between umbilicus and symphysis pubis 2- Waist hip ratio pre-and post-operatively at 1 and 6 months. 3- Evaluation of ventilatory function using spirometry and intraoperative measurement of intra-abdominal pressure before and after plication.

Results: Post-operative follow-up time averaged 8 months (range 6-10 months). Group A showed significant decline in the diastasis distance and increase in WHR than group B. There was a significant reduction in spirometry values and increase in IAP in group A rather than group B after surgery but there was no clinical differences in the respiratory function between both groups.

Conclusion: Plication of the anterior rectus sheath using myofascial repair technique showing nonsignificant residual diastasis six months post operatively and has a better effect on the waist enhancement than the conventional plication with no respiratory complication.

Key Words: Rectus abdominis - Diastasis - Techniques.

\section{INTRODUCTION}

Abdominoplasty aims to correct the anterior abdominal wall deformities through resection of redundant skin and musculoaponeurotic reinforcement. The goal of any abdominoplasty procedure is to increase the resultant aesthetic outcomes through correcting the abdominal laxity, improving the waist defintion, and restoring the lean curvatures [1].

Correction of rectus diastasis is a procedure very frequently performed during abdominoplasty [1-3]. Several techniques of fascial plasty of the anterior abdominal wall have been described to improve abdominal contour. These techniques includes Plication from a transverse to vertical orientation, at single or multiple sites using absorbable or nonabsorbable sutures [2-4]. However, midline plication of the rectus sheath all through its length from origin to insertion has remained the most popular method of reducing musculoaponeurotic laxity $[\mathbf{5 , 6 ]}$.

The durability of the pliction was an important issue to discuss beside its effect on waist enhancement, the restoration of a proper waist is becoming more and more one of the most frequent inquiry asked by patients. So, procedures focusing on correction of the stretched and thinned and diastatic sheath have been described to achieve lean curvature and more harmonious contour of the anterior abdominal wall $[7,8]$.

The search for the best and safest technique for enhancement of the waist during correction of the abdominal myoapponeurotic laxity is still going involving $\mathrm{L}$ and inverted $\mathrm{L}$ plication of the external oblique muscle and rectus abdominis myofascial release [9]. However, there is paucity of reserches evaluating durablity of these techniques.

That is why we aim in this study to prospectively evaluate the durability of the correction of two different methods used in rectus sheath plica- 
tion during abdominoplasty and its implication on waist definitin which are rectus abdominis myofascial release and convential mid line plication.

\section{PATIENTS AND METHODS}

Prospective, randomized study including 12 female patients seeking abdominoplasty with body mass index less than 30 having Rohrich type IV B deformities in the period from November 2016 to December 2018. Age ranging from 31-43 years. Patients with comorbidities especially respiratory disorders, previous abdominal surgery and BMI $>30$ were excluded from the study.

Detailed history was taken and clinical examination was done for assessment of body mass index, presence/absence of hernias and confirmation of rectus diastasis. All patients underwent a C-T scan on the abdomen pre-operatively to assess the distance of rectus diastasis at 3 points: (A) At the umbilicus, (B) Midway between umbilicus and xiphoid process and (C) Midway between umbilicus and symphysis pubis. Routine pre-operative investigations were done to all patients. Pre and postoperative anterior photographs were taken.

All patients had foley catheter inserted preoperatively to measure the vesical pressure which directly reflects the intraabdominal pressure [10].

After muscle relaxation and when the intravesical volume is below the volume required to initiate the bladder muscle contraction (approximately $350 \mathrm{ml}$ ). This volume was achieved by emptying the bladder and inserting $350 \mathrm{ml}$ of normal saline. All manometric measurements were obtained when the zero standard level was at the level of the patient's heart and recorded in centimeters of saline. Measurements was recorded preoperatively after initiation of anesthesia and postoperatively while the patient was still intubated and fully relaxed.

Standard abdominoplasty under general anesthesia was performed in all patients, then the patients were divided randomly into two groups based on the technique used for anterior rectus sheath plication: Group (A) included 6 patients who underwent the rectus abdominis myofascial release technique (Ramirez, 2000) [9]; this was done by incising the anterior rectus sheath longitudinally at the junction between the inner and the middle thirds of the rectus muscle width. In cases of significant abdominal laxity, this incision is made at about half of the rectus width. These incisions meet at the level of the xiphoid process superiorly and the pubis inferiorly. The medial edges are sutured together using round nylon loop 0 sutures and the lateral edges sutured together using the same kind of suture (Fig. 1).

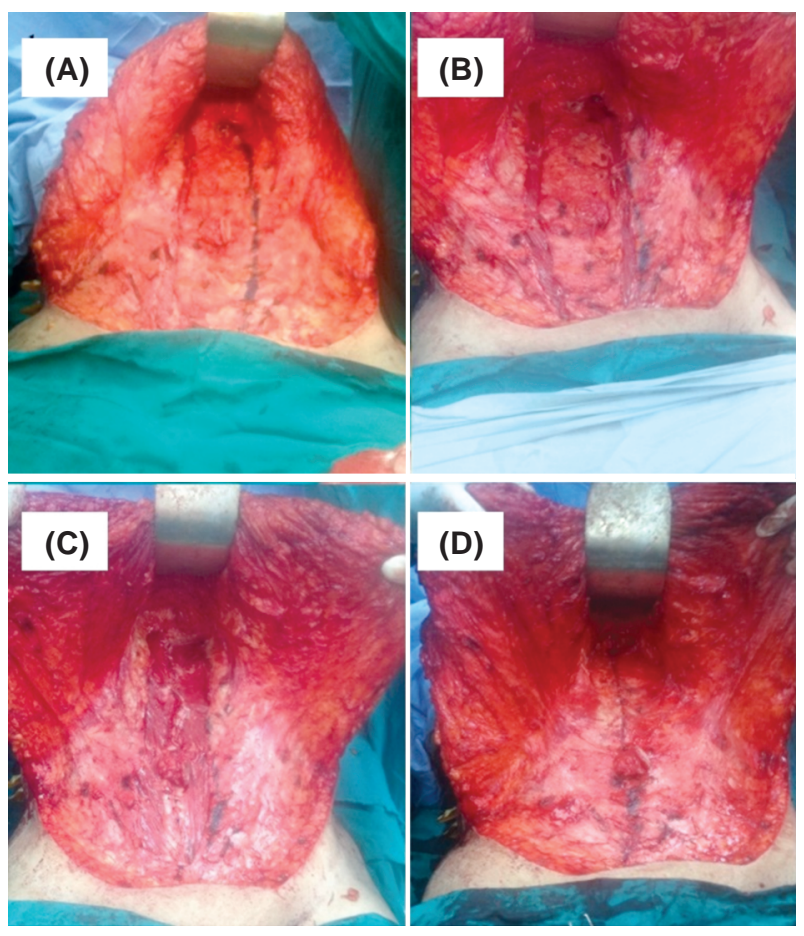

Fig. (1): (A) Incision of the right anterior rectus sheath, (B) Incision of the left anterior rectus sheath, (C) Suturing of the medial edges, (D) Suturing of the lateral edges.

Group (B) included 6 patients who underwent conventional midline plication of the rectus sheath using rounded nylon loop 0 sutures in a continuous fashion.

The two groups were compared using three methods:

1- The width of rectus diastasis; using computed tomography of their anterior rectus abdominis muscle pre-operative and post-operatively at 1 and 6 months at 3 points:

A- At the umbilicus.

B- Midway between umbilicus and xiphoid process.

C- Midway between umbilicus and symphysis pubis.

2- Waist Hip Ratio (WHR); using a measure tape pre-operative and post-operatively at 1 and 6 months (the waist circumference was measured at a horizontal level $2 \mathrm{~cm}$ above the umbilicus and hip circumference was measured at the level of the greater trochanter).

3- Intra-Abdominal Pressure (IAP) before and after plication of the anterior rectus sheath was measured intraoperatively and its effect on ventilatory 
function was assessed by using pre-and 1 week post-operative spirometry (measuring the volume of inhaled and exhaled air and respiratory flows, beneficial in analysis of data resulting from forced expiratory maneuver and the Peak Expiratory Flow (PEF) [11].

In addition; complications as seroma, hematoma, infection, wound dehiscence and others were recorded.

Statistical analysis were done for the collected data through Statistical Package for the Social Sciences (SPSS) program, Version 20. Standard methods of descriptive statistics were used (mean, median, standard deviation). In a symmetric distribution of frequencies we applied parametric statistical analysis (student's $t$-test) and in asymmetric distribution, nonparametric statistical analysis methods ( $\chi^{2}$ test and Mann-Whitney test). Fisher's exact test was used for comparing frequency of success in two treated groups. The value of $p \leq$ 0.05 was considered as significant.
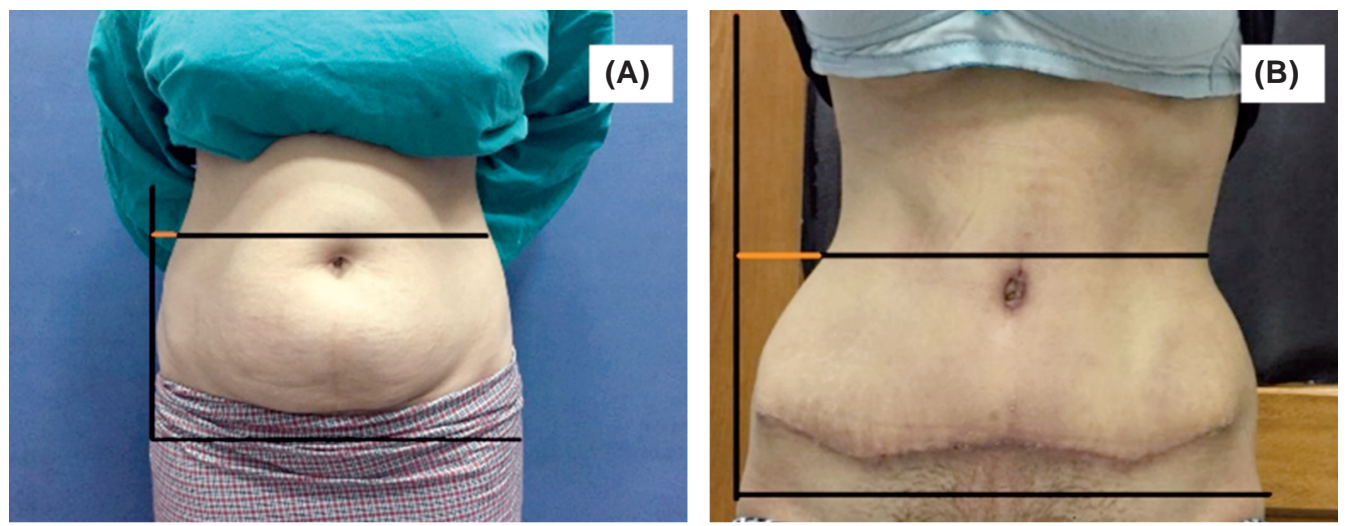

Fig. (2): Female patient 32 years old underwent myofascial release technique (A) Anterior view pre-operative, (B) Anterior view post-operative. The orange line represents the Waist Hip Ratio (WHR).
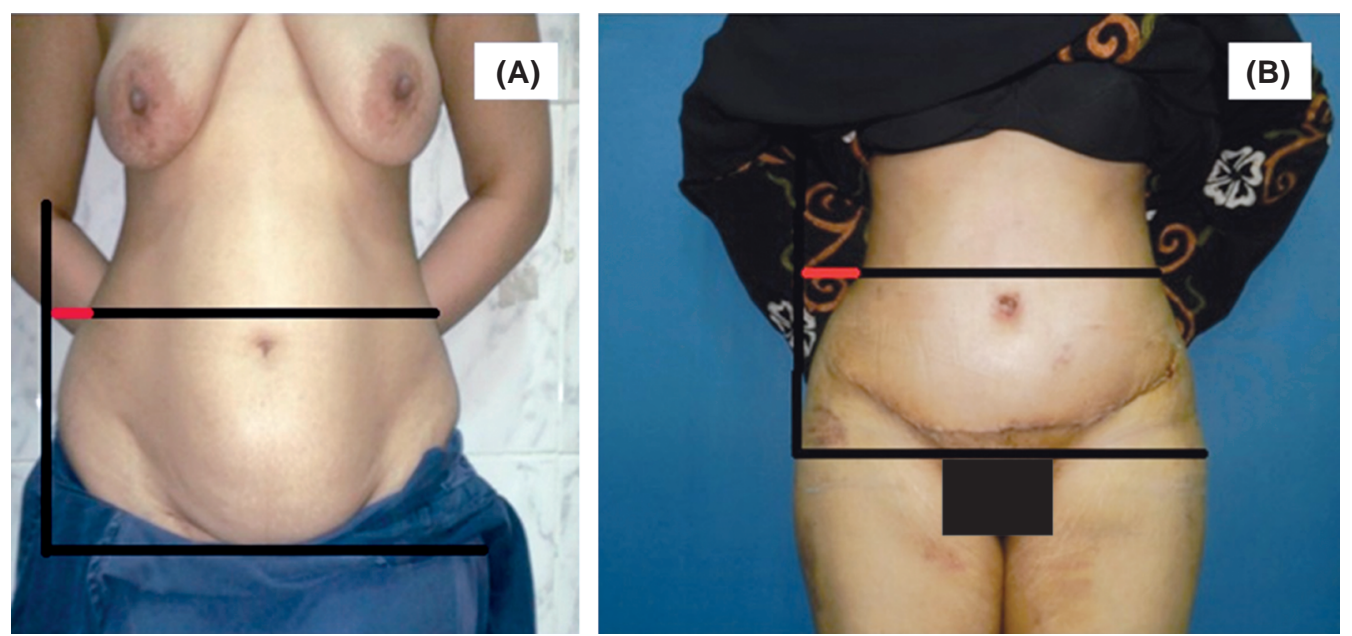

Fig. (3): Female patient 30 years old underwent convential midline plication technique (A) Anterior view preoperative, (B) Anterior view post-operative. The orange line represents the Waist Hip Ratio (WHR). 

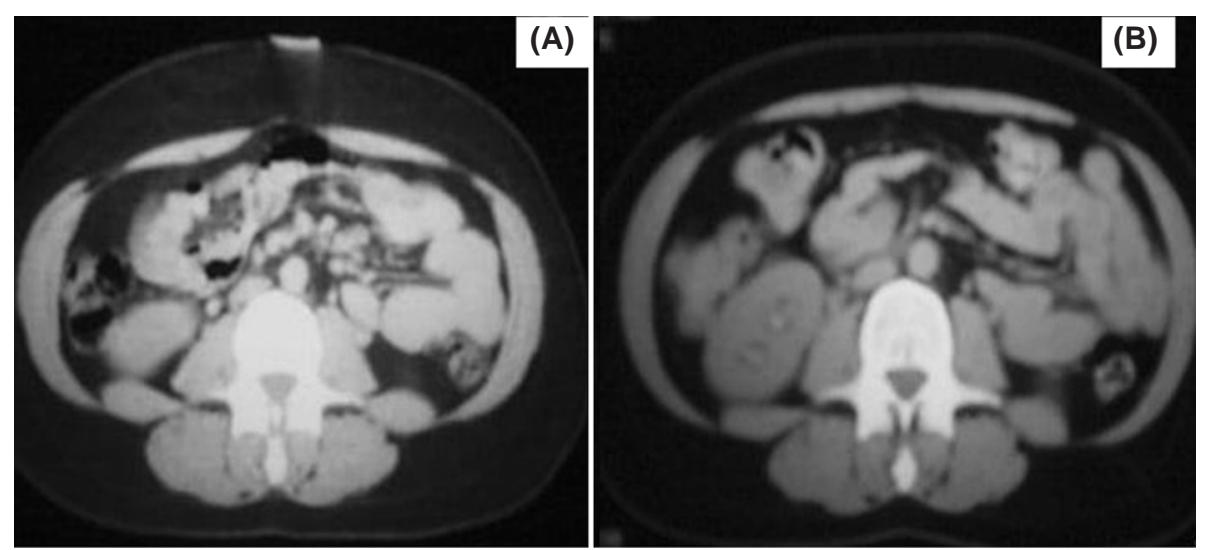

Fig. (4): (CT) scan slice midway between umbilicus and xiphoid process in 35 years old female patient of group A showing (A) Pre-operative 2.9-cm rectus diastasis. (B) 6 months post-operative slice showing total correction of diastasis.
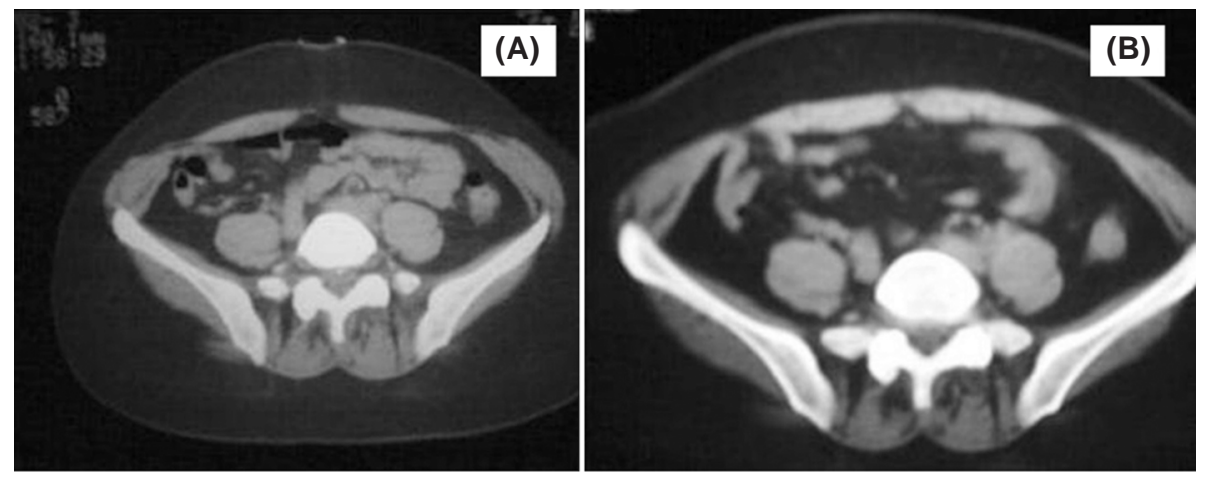

Fig. (5): (CT) scan slice midway between umbilicus and symphysis pubis in 39 years old female patient of group B showing (A) Pre-operative 2.2-cm rectus diastasis. (B) 6 months post-operative slice showing $0.4 \mathrm{~cm}$ residual diastasis but within normal regarding to Beer classification.

The mean pre-operative WHR in Group A was $1.13 \pm 0.03$, range $(0.95-1.26)$ and in group $\mathrm{B}$ was $1.12 \pm 0.02$, range $(0.92-1.30)$. There were no statistical difference between both groups.

All patients showed improvement of the waist post-operatively. The mean WHR after 1 month post-operatively in Group A was $0.70 \pm 0.02$, range (0.67-0.73) and in Group B was $0.73 \pm 0.03$, range (0.69-0.76) however this was of no statistically significant difference between both groups. At six months post-operatively, WHR in group A was $0.74 \pm 0.04$ range $(0.72-0.78)$ which was better and significant statistically than patients in group B $0.80 \pm 0.03$ range $(0.78-0.84)$.

The mean pre-plication IAP in Group A was $5.51 \pm 0.81$, range $\left(4.86 \mathrm{CM} \mathrm{H}_{2} \mathrm{O}-6.89 \mathrm{CM} \mathrm{H}_{2} \mathrm{O}\right)$ and the mean pre-plication IAP in Group B was 5.43 \pm 0.64 , range (4.16CM $\mathrm{H}_{2} \mathrm{O}-6.56 \mathrm{CM} \mathrm{H}_{2} \mathrm{O}$ ). There were no statistical difference between the two groups.

All patients showed an increase in IAP reflected by increased intra-vesical pressure after repair and plication of the musculoaponeurotic system. The mean IAP post-plication in Group A was $10.46 \pm$ 1.24 , range (8.74CM $\mathrm{H}_{2} \mathrm{O}-12.2 \mathrm{CM} \mathrm{H}_{2} \mathrm{O}$ ), and the mean post-plication IAP in Group B was $9.54 \pm 0.23$, range $\left(8.16 \mathrm{CM} \mathrm{H}_{2} \mathrm{O}-11.4 \mathrm{CM} \mathrm{H}_{2} \mathrm{O}\right)$. Patients in group (A) showed a higher increase in IAP than patients in group (B) however, there were no statistically significant difference and no postoperative respiratory complications in both groups.

The results of PEF values in the pre-and 1 week post-operative periods of patients in the two groups are shown in (Table 3). Statistical analysis showed no significant difference in the pre-operative values in between the two groups. Group B showed better PEF than group A at 1 week post-operatively with no statistically significant differences and no postoperative respiratory complication in both groups.

As regard complications in Group A, wound infection was occurred in one patients. In Group $\mathrm{B}$, wound dehiscence was occurred in one patients and seroma in another one. All were managed conservatively. None of them required secondary intervention. 
Table (1): Mean residual diastasis between the two groups.

\begin{tabular}{ccccccc}
\hline & $\begin{array}{c}\text { Above } \\
\text { umbilicus } \\
\text { pre }\end{array}$ & $\begin{array}{c}\text { Above } \\
\text { umbilicus } \\
\text { post }\end{array}$ & $\begin{array}{c}\text { At } \\
\text { umbilicus } \\
\text { pre }\end{array}$ & $\begin{array}{c}\text { At } \\
\text { umbilicus } \\
\text { post }\end{array}$ & $\begin{array}{c}\text { Below } \\
\text { umbilicus } \\
\text { pre }\end{array}$ & $\begin{array}{c}\text { Below } \\
\text { umbilicus } \\
\text { post }\end{array}$ \\
\hline $\begin{array}{l}\text { Group A: } \\
\text { Mean }\end{array}$ & $3.3 \pm 0.03$ & $0.5 \pm 0.02$ & $3.1 \pm 0.05$ & $0.3 \pm 0.06$ & $2.1 \pm 0.01$ & $0.2 \pm 0.04$ \\
Range & $2.8-4.1$ & $0.3-0.8$ & $2.4-3.7$ & $0.1-0.5$ & $1.8-2.5$ & $0.1-0.4$ \\
Group B: & & & & & & \\
Mean & $3.2 \pm 0.05$ & $1 \pm 0.04$ & $3.0 \pm 0.09$ & $0.8 \pm 0.02$ & $2.2 \pm 0.03$ & $0.6 \pm 0.01$ \\
Range & $2.2-4.5$ & $0.8-1.3$ & $2.4-4.8$ & $0.6-1.2$ & $1.9-3.5$ & $0.4-0.8$ \\
$p$-value & 0.765 & $0.017 *$ & 0.457 & $0.023^{*}$ & 0.654 & $0.014 *$ \\
\hline
\end{tabular}

(*): Statistically Significant at $p<0.05$.

Table (2): Beer classification.

\begin{tabular}{lcc}
\hline \multirow{2}{*}{ Level } & \multicolumn{2}{c}{ Normal width of the linea alba } \\
\cline { 2 - 3 } & $\begin{array}{c}\text { Age }<45 \\
\text { years }(\mathrm{mm})\end{array}$ & $\begin{array}{c}\text { Age }>45 \\
\text { years }(\mathrm{mm})\end{array}$ \\
\hline At the level of the xiphoid & 10 & 15 \\
$3 \mathrm{~cm}$ above the umbilicus & 27 & 27 \\
$2 \mathrm{~cm}$ below the umbilicus & 9 & 14 \\
\hline
\end{tabular}

\section{DISCUSSION}

Patients seeking abdominoplasty usually aim to get a more ideal contour of their silhouette [13], thus abdominoplasty must address not only skin and subcutaneous tissue but also the muscular abdominal wall to maximize aesthetic outcome of the procedure. The traditional method of tightening the abdomen and correcting diastasis of recti is by plication both intact anterior rectus sheath to each other. Manipulations of the musculoaponeurotic layer of the abdomen during abdominoplasty has been described by different authors using different techniques in efforts to enhance the waistline [4,14-16].

The durability of plication has been evaluated by a number of studies $[\mathbf{1 7 , 1 8 , 2 3}$, but the use of retrospective methodology, small sample size and a short-term follow-up have been limiting factors [19]. This prospective study compared two techniques for correction of rectus diastasis, the rectus abdominis myofascial release technique and the conventional midline plication technique as regard the durability of the correction and the residual diastasis persist six months postoperatively and their effect on waist enhancement and the safety in terms of the intraabdominal pressure changes and respiratory affection that occur after plication in patients who underwent abdominoplasty.

Measuring of the rectus diastasis has been performed in different studies either using Com-
Table (3): Measurements of PEF pre and 1 week postoperatively in both groups.

\begin{tabular}{lll}
\hline & \multicolumn{1}{c}{ PEF pre } & \multicolumn{1}{c}{ PEF post } \\
\hline Group A & $485.4 \pm 70.9$ & $354.2 \pm 81.2$ \\
Group B & $478.9 \pm 67.1$ & $381.9 \pm 80.3$ \\
$p$-value & 0.116 & 0.181 \\
\hline
\end{tabular}

puted Tomography (CT), ultrasound or Magnetic Resonance Imaging (MRI) [2,20-22]. Ultrasound has been shown to be non-invasive, inexpensive and repeatable without any exposure to radiation, however it was seen inaccurate in the infraumbilical area and operator-dependent. The MRI proved to be safe, with great dependability as it is not operator-dependent. However it is not costeffective and we think it cannot be used as a routine tool for abdominoplasty. CT has the advantage of using bony points for measurement and thus give precise measurements.

Van Uchelen et al., [3] evaluated the long-term durability of vertical plication with ultrasonography and the post-operative effect of abdominoplasty on the waist definition, they founded residual or recurrent diastasis in 40 percent of the patients. As regard the effect of plication on the waist, they detected 67 percent of patients felt it was unchanged and 33 percent felt their waist had become slimmer. They stated that vertical plication alone was not enough to improve the waistline and could eventually lead to epigastric bulging.

Tadiparthi et al., [19] showed that none of the patients in their study had recurrent diastasis and all ultrasound measurements at the 12-month postoperative period were within those defined by Beer.

In a study done by Mestak et al., [18] they evaluated the ultrasonographic measurements of the residual distance between rectus muscles in 
patient underwent convential midline plication of the rectus sheath. Their result were as following: At halfway between the xiphoid and umbilicus, the mean distance was $0.1 \mathrm{~cm}$; at the level just above the umbilicus, the mean distance was $0.87 \mathrm{~cm}$ and at halfway between the umbilicus and pubis, the mean distance was $0.08 \mathrm{~cm}$.

Another study used a midline vertical plication of the rectus muscle and the myofascial component was performed using a nylon 0-loop suture in continuous fashion from the xiphoid to the suprapubic region. The authors did not consider ultrasound as a suitable method of investigation for diastasis because it is operator-dependent. They used magnetic resonance imaging, and they found that there was no rectus diastasis seen in any of the cases followed-up between 6 and 25 months. The mean post-operative diastasis was $0.5 \mathrm{~cm} \mathrm{[23].}$

As regard the waist enhancement their data [23] was different from Van Uchelen et al., [3] they showed that the inner circumference and abdominal anteroposterior imaging measurements were decreased post-operatively compared with the preoperative measurements; which indicated a reduction in waist line in both the anteroposterior and transverse dimensions measured by magnetic resonance imaging. These changes may apparently due to change of shape of the muscle mass because of its fascial plication.

In this study we used a Computed Tomography (CT) for assessing the rectus diastasis. The postoperative measurements at 3 months of follow-up showed no diastasis between recti in both groups with no significant difference between both. However, at 6 months of the follow-up period the diastasis was detected in both groups but still the distance within normal as described by Beer et al., the mean in group A were $(0.5,0.3,0.2 \mathrm{~cm})$ at the 3 levels of measurements above the umbilicus, at the umbilicus, below the umbilicus respectively which were minimal than that for group B $(1,0.8$, $0.6 \mathrm{~cm})$ and the difference was significant statistically which may determine the durability of the plication using myofascial release rather than using the conventional method.

As regard the waist definition, in this study, the data demonstrate consistent reductions in waist diameter in all patients from both groups and all patients noticed the reduction in their waist diameter after the operation. However, patients in Group A showed a statistically significant better improvement of the WHR than patients in Group B six months after the operation.
Increased intraabdominal pressure is common after abdominoplasty especially with the manipulation of the musculoaponeurotic layer. The intraabdominal hypertension may result in elevation of intrathoracic pressure leading to pulmonary complications [24-26]. On the other hand, some other studies claimed that there were no significant differences in lung function and IAP were found after abdominoplasty with plication $[\mathbf{2 7}, \mathbf{2 8}]$.

Talisman et al., [29] proved that the Intraabdominal Pressure (IAP) increases after the manipulation of the abdominal musculoaponeurotic structures and showed a direct relationship between the increased IAP and a higher incidence of respiratory complications.

Neto et al., [30] performed analysis of postoperative intraabdominal pressure after abdominoplasty. All subjects of their study were healthy female with ages varying from 28 to 47 years old, which is similar group of patients like in this study. They reported complications of two cases with mild dyspnea, characterized by tachypnea without radiographic, laboratory or chest auscultation changes. In this study there were no post-operative respiratory complications.

In both studies monitoring of IAP was performed through a bladder catheter, which is a simple, minimally invasive, low-cost and easily performed method. IAP of their study vary from $12-13 \mathrm{~cm} \mathrm{H}_{2} \mathrm{O}$. In this study values of post-operative IAP were lower with group $\mathrm{B}$ ranging between (8.16CM $\mathrm{H}_{2} \mathrm{O}-11.4 \mathrm{CM} \mathrm{H}_{2} \mathrm{O}$ ), while in a group $\mathrm{A}$ was between (8.74CM H $\mathrm{H}_{2} \mathrm{O}-12.2 \mathrm{CM} \mathrm{H}_{2} \mathrm{O}$ ).

Al-Basti et al., [30] studied the intraabdominal pressure changes after full abdominoplasty in obese multiparous patients, they were performing the conventional vertical plication of the rectus fascia technique for all patients, and they discovered that the increase in intraabdominal pressure is not statistically or clinically significant.

In this study, we found that IAP was higher in group A than group B but there was no clinical or statistically significant difference between the two performed techniques.

Rodrigues et al., [28] stated that the changes in the intraabdominal pressure recording before and after repair of the musculoaponeurotic system are considered statistically significant and clinically non-significant. It is an indication of the real tolerance of the abdominal cavity in adjustment and its accommodation to its normal content. There- 
fore, abdominal cavity tolerance depends on whether the abdominal contents are normal and the absence of severe pathologic abnormalities in the musculoaponeurotic system.

As regard the ventilatory function, any abdominal surgery can affect ventilatory function, especially procedures involving a muscle. Some studies [24,32-34] addressed ventilatory function after the plication of the anterior rectus sheath. Gabriel et al., [32] detected a significant reduction in spirometry values after surgery, and proved that there was no correlation between Body Mass Index (BMI), pain, the increase of IAP, and the width of diastasis and changes in spirometry $(p \leq 0.05)$ in any of the post-operative evaluations. They stated that the Spirometric parameters change on the $2^{\text {nd }}$ and 7 th post-operative days and tend to normalize on the $15^{\text {th }}$ day.

In this study we measured peak expiratory flow PEF pre and one week post-operatively. There was no significant difference in the pre and postoperative values between both groups, however, PEF was higher in group B rather than group A. which may indicate more compression in group A that affect the ventilator function, but not to a limit that require any intervension. We thought that changes in ventilatory function may be due to increased IAP in group A than in group B.

The limitations of this study are the limited period of follow-up and the relatively small number of cases included. On the basis of this study, it is recommended that a further investigations to be done on a wider scale of cases.

\section{Conclusion:}

The rectus abdominis myofascial release technique, although more invasive, it was more durable in the correction of the rectus diastasis, and has a better effect on the waist enhancement more than the conventional method, with no respiratory complication.

\section{REFERENCES}

1- Chaouat M., Levan P., Lalanne B., Buisson T., Nicolau P. and Mimoun M.: Abdominal dermolipectomies: Early postoperative complications and long-term unfavorable results. Plast. Reconstr. Surg., Dec., 106 (7): 1614-8; discussion 1619-23, 2000.

2- Nahas F.X., Augusto S.M. and Ghelfond C.: Nylon versus polydioxanone in the correction of rectus diastasis. Plast. Reconstr. Surg., 107: 700e6, 2001.

3- Van Uchelen J.H., Kon M. and Werker P.M.: The longterm durability of plication of the anterior rectus sheath assessed by ultrasonography. Plast. Reconstr. Surg., 107: 1578e84, 2001.

4- Yousif N.J., Lifchez S.D. and Nguyen H.H.: Transverse rectus sheath plication in abdominoplasty. Plast. Reconstr. Surg., 1; 114 (3): 778-84, 2004.

5- Baroudi R. and Ferreira C.A.: Contouring the hip and the abdomen. Clin. Plast. Surg., Oct., 23 (4): 551-72; discussion 572-3, 1996.

6- Nahas F.X.: Advancement of the external oblique muscle flap to improve the waistline: A study in cadavers. Plast. Reconstr. Surg., Aug., 108 (2): 550-5, 2001.

7- Nahas F.X., Augusto S.M. and Ghelfond C.: Should diastasis recti be corrected? Aesthetic. Plast. Surg., Jul.Aug., 21 (4): 285-9, 1997.

8- Akram J. and Matzen S.H.: Rectus abdominis diastasis. J. Plast. Surg. Hand Surg., Jun., 48 (3): 163-9, 2014.

9- Ramirez O.M.: Abdominoplasty and abdominal wall rehabilitation: A comprehensive approach. Plast. Reconstr. Surg., Jan., 105 (1): 425-35, 2000.

10- Manu L.N.G. Malbrain, Nele Desie, Alexandra Willems, Inneke De laet, Hilde Dits, Niels Van Regenmortel, Karen Schoonheydt and Martine Van De Vyvere: Intra-abdominal pressure measurement using the Foley Manometer does not increase the risk for urinary tract infection in critically ill patients Annals of Intensive Care, December, 2: S10, 2012.

11- American Thoracic Society: Lung function testing. Selection of reference values and interpretative strategies. American Review of Respiratory Diseases, 144: 12021218, 1991.

12- Beer G.M., Schuster A., Seifert B. and Manestar M.: The normal width of the linea alba in nulliparous women. Clin. Anat., 22: 706-711, 2009.

13- Fisher M.L. and Voracek M.: The shape of beauty: Determinants of female physical attractiveness. J. Cosmet. Dermatol., 5 (2): 190-4, 2006.

14- Ferreira L.M., Castilho H.T., Hochberg J., Ardenghy M., Toledo S.R., Cruz R.G. and Tardelli H.: Triangular mattress suture in abdominal diastasis to prevent epigastric bulging. Ann. Plast. Surg., Feb., 46 (2): 130-4, 2001.

15- Serra-Renom J.M., Martinez-Teixido L., Serra-Mestre J.M.: Abdominoplasty with Customized Transverse Musculoaponeurotic Plications. Plast. Reconstr. Surg., Dec., 136 (6): 741e-9e, 2015.

16- Gama L.J.M., Barbosa M.V.J., Czapkowski A., Ajzen S., Ferreira L.M. and Nahas F.X.: Single-Layer Plication for Repair of Diastasis Recti: The Most Rapid and Efficient Technique. Aesthet. Surg. J., Jun. 1, 37 (6):698-705, 2017.

17- Netscher D.T., Wigoda P., Spira M. and Peltier M.: Musculoaponeurotic plication in abdominoplasty: How durable are its effects? Aesthetic. Plast. Surg., 19: 531$534,1995$.

18- Mestak O., Kullac R., Mestak J., Nosek A., Krajcova A. and Sukop A.: Evaluation of the long-term stability of sheath plication using absorbable sutures in 51 patients with diastasis of the recti muscles: An ultrasonographic study. Plast. Reconstr. Surg., Nov., 130 (5): 714e-719e, 2012. 
19- Tadiparthi S.1., Shokrollahi K., Doyle G.S. and Fahmy F.S.: Rectus sheath plication in abdominoplasty: Assessment of its longevity and a review of the literature. J. Plast. Reconstr. Aesthet. Surg., Mar., 65 (3): 328-32, 2012.

20- Birdsell D.C., Gavelin G.E., Kemsley G.M. and Hein K.S.: "Staying power": Absorbable vs nonabsorbable. Plast. Reconstr. Surg., 68: 742, 1981.

21- Mendes D.A., Nahas F.X., Veiga D.F., et al.: Ultrasonography for measuring rectus abdominis diastasis muscles. Acta. Cir. Bras., 22: 182-186, 2007.

22- De Castro E.J., Radwanski H.N., Pitanguy I. and Nahas F.: Long-term ultrasonographic evaluation of midline aponeurotic plication during abdominoplasty. Plast. Reconstr. Surg., Aug., 132 (2): 333-8, 2013.

23- Elkhatib H., Buddhavarapu S.R., Henna H. and Kassem W.: Abdominal Musculoaponeuretic System: Magnetic Resonance Imaging Evaluation before and after Vertical Plication of Rectus Muscle Diastasis in Conjunction with Lipoabdominoplasty. Plast. Reconstr. Surg., 128: 733e740e, 2011.

24- Tercan M., Bekerecioglu M., Dikensoy O., Kocoglu H., Atik B., Isik D. and Tercan A.: Effects of abdominoplasty on respiratory functions: A prospective study. Ann. Plast. Surg., 49 (6): 617-620, 2002.

25- Watson R.A. and Howdieshell T.R.: Abdominal compartment syndrome. South Med. J., 91 (4): 326-332, 1998.

26- Pereira N., Sciaraffia C., Danilla S., Parada F., Asfora C. and Moral C.: Effects of abdominoplasty on intraabdominal pressure and pulmonary function. Aesthetic Surgery Journal, Feb. 9, 36 (6): 697-702, 2016.
27- Wilhelmsson S., Fagevik Olsén M., Staalesen T., Elander A. and Nygren-Bonnier M.: Abdominal plasty with and without plication-effects on trunk muscles, lung function, and self-rated physical function. J. Plast. Surg. Hand Surg., Jun., 51 (3): 199-204, 2007.

28- Rodrigues M.A., Nahas F.X., Gomes H.C. and Ferreira L.M.: Ventilatory function and intra-abdominal pressure in patients who underwent abdominoplasty with plication of the external oblique aponeurosis. Aesthetic Plast. Surg., Oct., 37 (5): 993-9, 2013.

29- Talisman R., Kaplan B., Haik J., Aronov S., Shraga A. and Orenstein A.: Measuring alterations in intra-abdominal pressure during abdominoplasty as a predictive value for possible post-operative complications. Aesthetic Plast. Surg., 26 (3): 189-192, 2002.

30- Neto L.G., Araujo L.R., Rudy M.R., Auersvald L.A. and Graf R.: Intraabdominal Pressure in Abdominoplasty Patients. Aesth. Plast. Surg., 30: 655-658, 2006.

31- Al-Basti H.B., El-Khatib H.A., Taha A., Sattar H.A. and Bener A.: Intraabdominal pressure after full abdominoplasty in obese multiparous patients. Plast. Reconstr. Surg., Jun., 113 (7): 2145-50; discussion 2151-5, 2004.

32- Gabriel A., Gupta S.C. and Freeman B.G.: Abdominoplasty. eMedicine. http://www.emedicine.com/plastic/topic12. HTM. Accessed 12 Nov 2010, 2010.

33- Saggi B.H., Sugerman H.J., Ivatury R.R. and Bloomfield G.L.: Abdominal compartment syndrome. J. Trauma, 45 (3): 597-609, 1998.

34- Hewlett A.M. and Branthwaite M.A.: Post-operative pulmonary function. Br. J. Anaesth., 47 (2): 102-107, 1975. 